
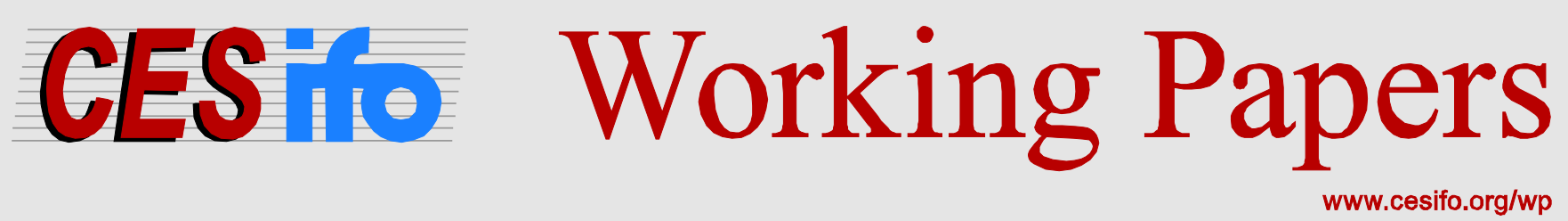

\title{
The Hidden Cost of Globalization: Import Competition and Mental Distress
}

\author{
Italo Colantone \\ Rosario Crinò \\ Laura Ogliari
}

CESIFO WORKING PAPER NO. 5586

CATEgory 8: TRAde Policy

OCTOBER 2015

An electronic version of the paper may be downloaded

- from the SSRN website:

- from the RePEc website:

- from the CESifo website:

wWw.SSRN.com

www.RePEc.org

www.CESifo-group.org/wp 


\title{
The Hidden Cost of Globalization: Import Competition and Mental Distress
}

\begin{abstract}
We study the effect of import competition on workers' mental distress. To this purpose, we source information on the mental health of British workers from the British Household Panel Survey, and combine it with measures of import competition in more than 100 industries over 2001-2007. We find an increase in import competition to have a positive, statistically significant, and large impact on mental distress. The effect is strikingly robust to controlling for a wide range of individual, household, and industry characteristics. We show that part of the effect is due to import competition worsening the current labor market situation of individuals, in terms of higher probability of job displacement and lower wage growth. Additionally, and most importantly, we show that import competition worsens mental health also for individuals witnessing no change in observable labor market conditions, by increasing stress on the job and worsening expectations about the future.
\end{abstract}

JEL-Codes: F100.

Keywords: subjective well-being, trade adjustment costs, individual-level panel data.

\author{
Italo Colantone* \\ Bocconi University \\ Via Roentgen 1 \\ Italy-20136 Milan \\ italo.colantone@unibocconi.it
}

\author{
Rosario Crinò \\ Catholic University of Milan \\ Department of Economics and Finance \\ Via Necchi 5 \\ Italy - 20123 Milan \\ rosario.crino@unicatt.it
}

\author{
Laura Ogliari \\ Bocconi University \\ Via Roentgen 1 \\ Italy-20136 Milan \\ laura.ogliari@unibocconi.it
}

*corresponding author

October 2015

We thank Jerome Adda, Carlo Altomonte, Manuel Arellano, Lorenzo Caliendo, Anne-Marie Jeannet, Rafael Lalive, Myriam Mariani, Francesco Passarelli, Fabiano Schivardi, and seminar participants at Bocconi University, LUISS University, University of Ancona and the 2015 iHEA Conference in Milan for helpful comments. Rosario Crinò gratefully acknowledges financial support from Fundación Ramón Areces. The usual disclaimer applies. 


\section{Introduction}

A proper assessment of the net welfare gains from trade is one of the most important, yet highly controversial, issues in economics. The traditional approach in the literature is to study how standard measures of welfare (e.g., real wages) change with trade liberalization. Recent and influential studies have started to provide an increasingly precise assessment of the adjustment costs of trade, and to explore their implications for welfare (see, most notably, Autor et al., 2013, 2014). However, the focus of these studies has been limited to labor market outcomes, such as individuals' earnings and employment status. In this paper we shed the first light on a new trade adjustment cost: the impact of import competition on individuals' subjective well-being. We show, in particular, that import competition determines a severe worsening of individuals' mental health: a hidden, yet economically important, cost of globalization. Overall, we argue that neglecting how individuals' mental health responds to globalization could lead to a significant overestimation of the net gains from trade.

Our analysis builds on a unique data set. We combine longitudinal data on mental health for a representative sample of British workers over 2001-2007 (sourced from the British Household Panel Survey) with measures of import competition in more than 100 industries covering the entire UK economy. Our first result is that import competition substantially raises mental distress, as measured by the Generalized Health Questionnaire indicator (GHQ-12). Quantitatively, we find that a one standard deviation increase in import competition worsens mental health by 1.2 percentage points, explaining roughly $13 \%$ of the within-individual standard deviation in mental distress. Our second result is that the effect of import competition works through a complex set of mechanisms. In particular, we show that import competition increases mental distress by worsening the current labor market situation of individuals, in terms of higher probability of job displacement and lower wage growth. Additionally, and most importantly, we find import competition to worsen mental health also for workers witnessing no change in observable working conditions, by increasing stress on the job and worsening expectations about the future. The 
latter channels reach beyond conventional labor market mechanisms.

The UK is a very interesting context for studying the impact of import competition on mental distress, for three main reasons. First, mental health is a major concern in the UK. In 2007, 8.65ML people suffered from mental health problems, and treating mental distress was one the government's three clinical priorities, alongside cancer and health diseases (McCrone et al., 2008). The overall cost of mental health (including treatment services and employment losses) reached 49BN British pounds, roughly 3.5\% of GDP (McCrone et al., 2008); moreover, the additional costs due to absenteeism and presenteeism were estimated around 8.8BN pounds (Cooper and Dewe, 2008). Second, trade integration in the UK entailed a sharp increase in import competition: between 1995 and 2007, real imports increased by $75 \%$, much more than real exports and output, which rose by $52 \%$ and $27 \%$, respectively. Finally, the UK is the only country with panel-level data on mental health available for a nationally representative sample of individuals, over a long time span.

Our identification strategy consists of comparing changes in mental health across similar individuals, who are employed in similar industries except for the import competition shock. The BHPS database contains a wealth of information on observable worker characteristics. Moreover, being a panel data set, it offers repeated information on mental health for each individual. This allows us to condition the estimation on individual fixed effects, which remove differences in the level of mental health across individuals, and allow us to only exploit time variation in mental distress for the same person. One concern with our identification strategy is that unobserved demand shocks may simultaneously raise imports and improve individuals' subjective well-being, thereby inducing a downward bias in OLS estimates. To address this concern, in the spirit of Autor et al. (2013, 2014), we instrument import penetration using non-UK exports to the rest of the world. This instrument isolates the variation in import competition due to supply shocks in the exporting countries, rather than to UK-specific demand shocks.

Our baseline estimates reveal a quantitatively large impact of import competition on mental distress. This effect is remarkably robust to a large range of sensitivity checks. In 
particular, we find similar effects when: (1) using alternative measures of mental health; (2) employing alternative instruments, which are less likely to reflect correlated demand shocks across countries; (3) controlling for pre-existing industry trends and contemporaneous shocks; and (4) addressing the possibly non-random sorting of individuals across industries.

We find the effect of import competition to be relatively stable across individuals of different age, gender, and tenure within the firm, as well as across full-time and part-time employees, or across permanent and temporary workers. The effect is instead milder for the self-employed-which mostly operate in market niches and low tradable jobs that are little exposed to foreign competition-and larger for service sector employees—a result that reflects the strong specialization of the UK economy in services. Consistently, we find the impact of Chinese import competition (mostly contained to manufacturing) to be smaller than that of import competition from other countries.

Next, we explore several mechanisms through which import competition may work. Our empirical strategy consists in a two-step approach similar to Heckman et al. (2013). In the first step, we regress mental health on proxies for each mechanism. In the second step, we regress these proxies on changes in import competition. If a given mechanism is relevant, both regressions will deliver a statistically significant coefficient. The first mechanism we consider is related to job switching and displacement. We find import competition to be associated with a substantial increase in the probability of switching out of employment. In turn, leaving employment is associated with a large increase in mental distress. The second mechanism is related to changes in wages. Focusing on the sub-sample of workers who remain employed, we find import competition to lower wage growth, and this, in turn, to induce a substantial increase in mental distress.

The third and fourth mechanisms reach beyond the directly observable labor market conditions, such as job status and wages. In particular, the third mechanism relates to changes in job satisfaction. Focusing on employed workers and controlling for the observed change in wages, we find import competition to be associated with a worsening 
of individuals' satisfaction with their current job, mostly through an increase in workload (hours worked) and stress on the job. In turn, this is associated with a substantial increase in mental distress. Finally, the fourth mechanism relates to changes in expectations about the future. Controlling for changes in job status, wage growth, and job satisfaction, we find import competition to worsen individuals' expectations about opportunities for job promotion and training, as well as about their future financial situation. This, in turn, leads to higher mental distress. Using structural equation modeling we find that these four mechanisms mediate a non-negligible $26 \%$ of the effect of import competition on mental distress. Overall, these results imply that import competition works not just through standard labor market mechanisms (changes in job status and wages), but also through other channels related to job satisfaction and future expectations. As a result, import competition also affects workers who experience no change in their observable working conditions.

The rest of the paper is organized as follows. Section 2 discusses the related literature. Section 3 presents the data and the main variables used in the analysis. Section 4 illustrates our empirical specification and identification strategy. Section 5 presents the empirical results. Section 6 concludes.

\section{Related Literature}

Our paper is related to several strands of empirical research. First, we contribute to the growing literature on the labor market implications of trade and import competition (see, in particular, Bernard et al., 2006; Khandewal, 2010; Autor et al., 2013, 2014, 2015ab; Crinò and Epifani 2014a,b; Dauth et al., 2014; and Acemoglu et al., 2015). These papers find import competition to worsen workers' labor market conditions, in terms of higher probability of job displacement and lower wage growth. Nevertheless, the overall effect of import competition on welfare is usually estimated to be positive, thanks to the reduction in output prices and the larger set of varieties brought about by cheaper foreign goods (Goldberg et al., 2010). None of these studies however considers the subjective well-being of individuals. Our key contribution is to argue that, by increasing mental distress, import compe- 
tition may imply additional, and potentially large, adjustment costs, which should not be neglected in a proper assessment of the net welfare gains from trade.

Second, our paper is related to the small literature on the effects of trade on the diffusion of infectious diseases (Levine and Rothman, 2006; Owen and Wu, 2007; Oster, 2012) and mortality (Adda and Fawaz, 2015). The results of this literature are mixed, and none

of the existing papers focuses on mental health. We are the first to: $(a)$ show how import competition affects individuals' mental distress; and $(b)$ carefully document the mechanisms underlying this effect.

Finally, we connect with the broader literature on the economic determinants of mental health. This literature shows that mental distress is highly sensitive to changes in economic factors such as income and job status (see, e.g., Smith, 1999; Ruhm, 2000; Clark, 2003; Di Tella et al., 2007; Sullivan and von Wachter, 2009; Marcus, 2013; McInerney et al., 2013; Schwandt, 2014; Farrè et al., 2015). Mental distress is also found to respond to changes in environmental conditions, such as local area crime or neighborhood quality (Katz et al., 2001; Kling et al., 2007; Ludwig et al., 2012; Cornaglia et al., 2014; Dustmann and Fasani, 2015). Our contribution is to provide the first evidence that import competition is an additional, first-order determinant of workers' mental distress.

\section{Data and Variables}

Our main data source is the British Household Panel Survey (BHPS). This database covers a representative sample of the British population aged 16 or more, between 1991 and 2008. Importantly, each individual is interviewed every year, so the BHPS is a panel data set. The survey is household based, meaning that each person within a household is interviewed every year, and keeps being interviewed when she leaves the original household to form a new one, together with all the new family members. We focus on seven waves of the survey, spanning the period 2001-2007. This allows us to have import competition measures for both manufacturing and service industries (details below), and to exclude the recent financial crisis. Overall, in our regressions we use approximately 50,000 individual- 
year observations, corresponding to 12,748 individuals observed on average for 5.4 years. About $22 \%$ of individuals are interviewed in all seven waves.

Our main proxy for mental health is the 12-item version of the Generalized Health Questionnaire indicator (GHQ-12), which is available in each wave of the BHPS. GHQ-12 is widely used to detect psychiatric illness (Goldberg, 1978) and is nowadays the standard proxy for mental distress in studies on the economic and social determinants of mental health (see, most notably, Clark, 2003; Dustmann and Fasani, 2015). GHQ-12 is based on twelve questions related to three clinically meaningful factors: anxiety and depression, social dysfunction, and loss of confidence. Each question can be answered in four ways, denoting different levels of distress. Answers are assigned a value from 0 to 3 , so that higher numbers always indicate higher mental distress. The twelve questions and the four answers are listed in Table A1. The GHQ-12 indicator is obtained as the sum of the values taken by the answers to the twelve questions ('Likert scoring method'). As such, GHQ-12 ranges from 0 (least distressed) to 36 (most distressed). In our analysis, we normalize the index to range between 0 and 100, so as to interpret each regression coefficient as the percentage point effect of the corresponding variable on mental distress.

We assess the robustness of our results using a different scoring method, known as the 'Caseness bimodal scoring'. This assigns a 0 to the two answers corresponding to the lowest levels of distress, and a 1 to the two answers corresponding to the highest levels of distress. Accordingly, this alternative version of the GHQ-12 indicator ranges from 0 to 12 . Also in this case, we rescale the index between 0 and 100 .

The BHPS contains information on the industry of employment of each individual in each year. We use this information to match the individual-level data with proxies for import competition and other industry characteristics. Overall, we observe individuals employed in 122 industries. Of these, 103 are manufacturing industries, defined at the 3-digit level of the NACE Rev. 1.1 classification. The remaining industries belong to the service sector and are usually defined at the 2-digit level of the same classification. The 122 industries span the entire UK economy. 
We use the conventional definition of import competition, namely, the ratio of imports over apparent consumption (production plus imports minus exports). We source data on imports and exports from Comext (for the manufacturing industries) and WIOD (for the service industries). Production data come from the UK national statistical institute (for manufacturing) and WIOD (for services). Next, we define the import competition shock $\Delta I C_{j t-1}$ as the 5-year \% change in import competition in the industry $j$ in which a given worker was employed in year $t-1$. Such a shock is related to the mental distress of the same worker in year $t$. Because trade data for the service industries are only available since 1995, and we need 6 lags to construct this variable, our final estimation sample starts in 2001. We normalize the import competition shock by its standard deviation for ease of interpretation.

Finally, we complement these data with information on a wealth of other industry characteristics, which we use as control variables in our analysis. These include the 5-year change in real output, output price, employment share of high-skill workers, value added, and export intensity (exports-to-output ratio). We source these data from Comext, WIOD, and the UK national statistical institute.

Table 1 reports descriptive statistics on the individual-level variables. The average age of individuals in our sample is 41 years, and the sample is equally split between males and females. Roughly $93 \%$ of individuals are either employed or self-employed. Threefourths of the sample consists of individuals who are married or leave as a couple, $42 \%$ with no dependent children and $38 \%$ with some dependent child. Average household size is 3 persons. Almost $83 \%$ of individuals own a house, while $16 \%$ leave in a rented flat. Turning to the mental health indicators, GHQ-12 (normalized between 0 and 100) is equal to 30 on average, with an overall standard deviation of 14.2 and a within-individual standard deviation of 9.6. When separately considering the three components of GHQ-12, those related to anxiety and depression and social dysfunction are slightly higher, with a mean (standard deviation) of 30.8 (20.1) and 33.9 (12.7), respectively. ${ }^{1}$ The component related to

\footnotetext{
${ }^{1}$ The score on each of the three components of GHQ-12 is obtained by summing over answers to questions pertaining to each clinical dimension (details in Table A1). Each indicator is then normalized to range between
} 
loss of confidence is instead substantially lower, equal to 17.1 (standard deviation of 20.7).

As for the import competition shock, $\Delta I C_{j t-1}$ has a sample mean of 17.6 (standard deviation of 40.6), which implies that competitive pressure from foreign countries has substantially intensified over the period of analysis. The average figures mask however a significant degree of heterogeneity across industries. Figure 1 makes this point by showing the distribution of the average import competition shock across the 122 industries in our sample. As reported in Table 2, some industries (e.g., Mining and agglomeration of hard coal; Manufacture of televisions) have received very large positive shocks, close to $90 \%$ on average. Other industries (e.g., Manufacture of steam generators; Production of salt) have instead experienced a significant reduction in foreign competitive pressure. In our analysis, we will exploit this large variation in $\Delta I C_{j t-1}$ to identify the effect of import competition on mental distress.

\section{Empirical Specification}

We estimate specifications of the following form:

$$
M D_{i j t}=\alpha_{i}+\alpha_{j}+\alpha_{t}+\beta_{1} \Delta I C_{j t-1}+\mathbf{I}_{i t-1} \gamma^{\prime}+\mathbf{H}_{i t-1} \delta^{\prime}+\mathbf{S}_{j t-1} \lambda^{\prime}+\varepsilon_{i j t},
$$

where $M D_{i j t}$ is a proxy for the year $t$ mental distress of worker $i$, who was employed in industry $j$ in year $t-1 . \alpha_{i}, \alpha_{j}$, and $\alpha_{t}$ are individual, industry, and year fixed effects, respectively. $\Delta I C_{j t-1}$ is the import competition shock as defined above. $\mathbf{I}_{i t-1}, \mathbf{H}_{i t-1}$, and $\mathbf{S}_{j t-1}$ are vectors of controls for past individual, household, and industry characteristics, respectively, while $\varepsilon_{i j t}$ is an error term.

The individual fixed effects $\left(\alpha_{i}\right)$ soak up time-invariant differences in mental distress across individuals. Accordingly, for identification we only exploit variation in mental health and import competition for the same person over time. The vectors of control variables allow us to condition the estimation on a large set of time-varying observable characteristics

0 and 100. 
at the individual, household, and industry level. At the same time, the industry and time fixed effects absorb, respectively, time-invariant differences across industries and timespecific shocks that are common to all industries. In a nutshell, our identification strategy therefore compares changes in mental distress across similar workers, who live in similar households, and who are employed in similar industries except for the import competition shock.

Two concerns arise with the identification of our parameter of interest, $\beta_{1}$. The first is the possible endogeneity of $\Delta I C_{j t-1}$. Reverse causality should not be an issue in our case, because past changes in an industry's import competition are unlikely to be driven by the current realization of an individual's mental distress. Yet, endogeneity may arise as a result of omitted variables correlated with both $\Delta I C_{j t-1}$ and $M D_{i j t}$. For instance, a positive demand shock in an industry may be associated with an improvement in individuals' subjective well-being and simultaneously lead to higher imports, thereby inducing a downward bias in the OLS estimate of $\beta_{1}$. We address this concern by running instrumental variables (IV) regressions. In particular, we instrument $\Delta I C_{j t-1}$ using the 5-year \% change in non-UK exports to the rest of the world (i.e., all countries except the UK). Similar in spirit to Autor et al. $(2013,2014)$, this instrument is meant to isolate variation in UK imports due to supply shocks in the origin countries. The instrument is valid under two assumptions: (1) demand shocks are uncorrelated across countries, and (2) conditional on our large set of controls, there is no unobserved factor correlated with the instrument. We discuss the plausibility of these assumptions in the robustness section.

The second concern is the possible non-random assignment of workers to industries. This would not be an issue if workers remained in the same industry throughout the sample period. In this case, the individual fixed effects $\left(\alpha_{i}\right)$ would absorb compositional effects due to the non-random assignment of workers to industries. However, in our sample some workers do switch industries (24\% on average). Workers' movements may bias the coefficient of interest either upward or downward, depending on whether workers with worse mental conditions systematically switch to industries with higher or lower import compe- 
tition. To address this concern, we use two complementary approaches, similar to those developed by Dustmann and Fasani (2015) in their analysis of the effect of local area crime on mental health. First, we restrict to workers employed in a given industry for at least two consecutive years, and define a separate fixed effect for each worker-industry combination. This strategy implies that we only exploit variation in mental distress and import competition for a given worker while employed in the same industry. Second, we redefine the import competition shock at the 2-digit (rather than 3-digit) industry level. Using more aggregate data allays concerns with sorting, as individuals move less across broad 2-digit industries than they do across narrow 3-digit industries.

\section{Results}

We now present the empirical results. We start by providing extensive evidence that import competition is associated with a substantial increase in workers' mental distress (Section 5.1). Then, we study the mechanisms through which this effect takes place (Section 5.2).

\subsection{Import Competition and Mental Distress}

\subsubsection{Baseline Estimates}

The baseline estimates of eq. (1) are reported in Table 3. In column (1), we show OLS estimates of a parsimonious specification, in which GHQ-12 is regressed only on the import competition shock $\left(\Delta I C_{j t-1}\right)$ and individual fixed effects. Standard errors are corrected for clustering within individuals. ${ }^{2}$ The coefficient $\beta_{1}$ is positive and very precisely estimated, indicating that a larger rise in import competition in a worker's industry of employment is associated with a greater increase in mental distress.

In column (2), we estimate the same specification by Two-Stage Least Squares (2SLS), in order to account for the possible endogeneity of import competition. We instrument

\footnotetext{
${ }^{2}$ Alternative clustering schemes, e.g., clustering by 2-digit industry, deliver more precise estimates of our coefficient of interest. Hence, we show standard errors corrected for clustering by individuals, which yield the most conservative evidence.
} 
the change in import competition using the change in non-UK exports to the rest of the world. In the first-stage regression, the coefficient on the instrument (reported at the bottom of the table) has the expected positive sign, and it is large and very precisely estimated. The first-stage $F$-statistic is also very high, equal to 1907.1. This indicates that the instrument is very strong. At the same time, the second-stage coefficient $\beta_{1}$ remains positive and precisely estimated. The slight increase in the point estimate is consistent with there being unobserved demand shocks that increase imports and improve individuals' subjective well-being at the same time, thereby leading to a downward bias in the OLS estimate of $\beta_{1}$.

In column (3), we add a large set of controls for individual and household characteristics. These are: log age and its square, an indicator for physical health, household size, and dummies for educational level, marital and job status, household type, and home ownership (see Table 1 for details). ${ }^{3}$ The coefficient $\beta_{1}$ slightly increases and remains precisely estimated.

In column (4), we add a full set of industry and year effects. Our coefficient of interest is largely unchanged. Finally, in column (5) we add a large set of time-varying industry controls, which include the 5-year \% change in real output, output price, employment share of high-skill workers, value added, and export intensity. Including these controls leaves our main evidence unaffected and, if anything, implies a slight increase in the coefficient $\beta_{1}$.

Overall, these results indicate that import competition has a positive effect on individuals' mental distress. An individual working in an industry exposed to a stronger increase in foreign competition experiences a larger increase in her mental distress, as compared to a similar individual employed in an industry that witnesses a smaller import competition shock, ceteris paribus.

How strong is the effect of import competition? The point estimate in column (5) im-

\footnotetext{
${ }^{3}$ The indicator for physical health is based on 11 questions in the BHPS. Each question asks the respondent to report whether or not she suffered from a specific health problem in each year. The indicator is computed as the sum of the scores obtained in each question: zero in case of no problem, and one in case of reported problems. It is then normalized to range between 0 and 100. Specifically, the 11 health questions concern problems with: arms, legs, neck and the like (including arthritis and rheumatism); sight; hearing; skin conditions and allergies; chest/breathing; hearth/blood pressure and circulation; stomach, liver, kidneys and digestion; diabetes; epilepsy; migraine or frequent headaches; other.
} 
plies that a one standard deviation increase in $\Delta I C_{j t-1}$ leads to a 1.2 p.p. increase in GHQ12. The latter variable has an overall standard deviation of 14.2 and a within-individual standard deviation of 9.6. Hence, a one standard deviation increase in $\Delta I C_{j t-1}$ explains a sizable $8.5 \%$ (12.5\%) of the overall (within-individual) standard deviation of GHQ-12.

\subsubsection{Robustness Checks}

In this section, we submit our baseline estimates to a series of robustness checks.

Identification Our identification strategy requires demand shocks to be uncorrelated across countries. If this is the case, the correlation between our instrument and $\Delta I C_{j t-1}$ entirely stems from foreign supply shocks, which raise imports both into the UK and into other countries. If this assumption is instead violated, the IV estimates are biased in the same direction as the OLS estimates (i.e., downward), implying that our baseline coefficient in column (5) of Table 3 yields a lower bound of the effect of import competition on mental distress. We now perform different exercises to mitigate the influence of potential correlated demand shocks, and show that in most cases the estimated effect of import competition increases. The results are reported in Table 4, panel a).

In row (1), we reconstruct our instrument excluding the US and Canada from the importing countries. These two economies are similar to the UK in many respects, and their business cycle is significantly correlated with that of the UK (Artis et al., 2005; Hallet et al., 2006). Therefore, their demand shocks are more likely than those of other countries to be correlated with shocks occurring in the UK. In row (2) we do the same, but this time we exclude the US and Canada also from the exporting countries. This eliminates the additional concern that US and Canadian world exports may be driven by some demand shocks originating in the UK. In both cases, our main evidence is unchanged, and the coefficient $\beta_{1}$ is systematically larger than its baseline estimate.

Next, we re-estimate our baseline specification excluding industries where demand shocks are more likely to be correlated across countries. Following Colantone and Crinò (2014), these industries are: the five industries that are most sensitive to the business cycle, 
i.e. those characterized by the highest correlation between their own output and UK GDP (row 3 ); ${ }^{4}$ the five most energy-intensive industries (row 4$){ }^{5}$ and the seven industries originally identified by Autor et al. (2013) as having experienced substantial fluctuations over the sample period across countries, due to technological innovations, housing booms, and the rapid growth of emerging economies (row 5). ${ }^{6}$ Our coefficient of interest is positive, significant, and generally larger than the baseline estimate.

Contemporaneous shocks Our identification strategy also relies on the assumption that, conditional on the large set of controls included in the specification, the instrument is uncorrelated with the error term. This assumption would be violated in the presence of contemporaneous shocks correlated with the instrument and mental distress. In Table 4, panel b), we address this concern by augmenting our baseline specification with different sets of time fixed effects. As argued below, these fixed effects absorb most potential contemporaneous shocks, thereby further raising confidence in the validity of the exclusion restriction.

We start, in row (6), by replacing the year dummies with a full set of year-month dummies. In the BHPS, individuals are interviewed in different months. Given that mental health responds to seasonal factors such as the weather (e.g., Connolly, 2013), one may be concerned that our results are partly driven by the staggered timing of interviews in the BHPS. However, the inclusion of year-month dummies leaves our coefficient of interest unchanged.

Next, we study the implications of industry-specific shocks. Following Colantone and Crinò (2014), in rows (7)-(12) we divide industries into five bins of equal size, based on the

\footnotetext{
${ }^{4}$ These industries are: Manufacture of coke, refined petroleum products and nuclear fuel (NACE 23); Manufacture of rubber and plastic products (NACE 25); Manufacture of radio, television and communication equipment and apparatus (NACE 32); Air transport (NACE 62); Post and telecommunications (NACE 64).

${ }^{5}$ These industries are: Manufacture of pulp, paper and paper products (NACE 21); Manufacture of coke, refined petroleum products and nuclear fuel (NACE 23); Manufacture of chemicals and chemical products (NACE 24); Manufacture of other non-metallic mineral products (NACE 26); Manufacture of basic metals (NACE 27).

${ }^{6}$ These industries are: Manufacture of textiles (NACE 17); Manufacture of wearing apparel; dressing and dyeing of fur (NACE 18); Tanning and dressing of leather; manufacture of luggage, handbags, saddlery, harness and footwear (NACE 19); Manufacture of other non-metallic mineral products (NACE 26); Manufacture of basic metals (NACE 27); Manufacture of fabricated metal products, except machinery and equipment (NACE 28); Manufacture of office machinery and computers (NACE 30).
} 
observed change over the sample period in the variable indicated in each row. Then, we augment our baseline specification by including a full set of interactions between the time dummies and dummies for all bins. The idea is that industries that have experienced different changes in a given observable characteristic may also have been exposed to different shocks. These interactions soak up all time-varying differences across industries belonging to different bins. Accordingly, identification now only comes from the remaining variation in import competition across industries belonging to the same bin, which are relatively homogeneous. In a similar vein, in rows (13) and (14) we include full sets of interactions between the year dummies and either aggregate 2-digit industry or major occupation dummies. These interactions absorb shocks that hit all narrowly defined industries belonging to the same aggregate, or all occupations belonging to the same major category. Strikingly, our evidence is unchanged across the board.

Underlying trends An implicit assumption made so far is that industries follow parallel trends. Otherwise, the coefficient $\beta_{1}$ could reflect different pre-existing trends, rather than pick up the genuine causal effect of import competition. We now extend our specification to allow for heterogeneous trends based on pre-existing industry characteristics. The results are in Table 4, panel c). In rows (15)-(18), we augment our baseline specification by adding a full set of interactions between the year dummies and the initial value of the industry variables indicated in each row. In all cases, our main evidence is unchanged and the coefficient $\beta_{1}$ is generally larger than the baseline estimate.

Placebo tests We now perform two placebo tests to further show that our results do not reflect underlying factors correlated with general health and import competition. The results are in Table 4, panel d). In row (19), the dependent variable is our indicator of physical health rather than GHQ-12. The coefficient on import competition is now negative, very small and imprecisely estimated. This suggests that our results do not reflect underlying factors that correlate with import competition and the general health conditions of individuals. In row (20) we instead regress current mental health on future values of the import 
competition shock. The estimated coefficient is negative and not statistically significant, which further suggests that our results are not picking up common trends in imports and mental distress.

Sorting In panel e) of Table 4, we address concerns with the sorting of individuals across industries. As mentioned in Section 4, we use two complementary approaches. In row (21), we focus on individuals who stay in the same industry for two or more consecutive years, and add a different fixed effect for each individual-industry combination. In row (22), we instead compute the import competition shock at the 2-digit industry level. Our coefficient of interest remains positive, precisely estimated, and close to the baseline estimate. This suggests that the sorting of individuals across industries is not inducing any noteworthy bias in our estimates.

Alternative proxies for mental distress In Table 5, we finally show that our results are robust to the use of alternative measures of mental health. In row (1), we use the Caseness version of GHQ-12. The estimated coefficient is very close to our baseline estimate. In rows (2)-(4), we separately consider the three main components of GHQ-12 (Likert scoring method), i.e. anxiety and depression, social dysfunction, and loss of confidence. All coefficients are positive, and the first two are larger and more precisely estimated. This suggests that import competition affects all dimensions of mental distress, and especially those related to anxiety and depression, and to the satisfaction of individuals with day-today activities. Finally, in rows (5)-(16), we use as dependent variables the twelve individual components of GHQ-12. All estimated coefficients are positive and eight of them are also statistically significant, which further suggests that our results are not driven by just a few dimensions of mental distress.

\subsubsection{Heterogeneity}

In this section, we study whether the aggregate results presented above mask heterogeneity across individuals, sectors, and trading partners. The results are reported in Table 6. 
In panel a), we analyze the response of different groups of individuals to import competition. To this purpose, we interact $\Delta I C_{j t-1}$ with dummies for males, self-employed workers, older individuals (above 50 years of age), long-tenure workers (more than 10 years in the same job), permanent and full-time employees. We instrument each interaction with the interaction of our instrument and the corresponding dummy. We include these new variables both individually (columns 1-6) and jointly (column 7). We find no statistically significant differences across individuals of different gender, age, and tenure, nor across full-time and part-time employees or across permanent and temporary workers. We instead find a significantly smaller effect for the self-employed. Overall, this suggests that the impact of import competition on mental health is relatively homogeneous across different groups of individuals. Yet, self-employed workers seem to suffer less, which is consistent with these workers operating in market niches or low tradable jobs that are little exposed to foreign competition.

Next, we study heterogeneity across sectors. To this purpose, we split the sample in two parts, corresponding to manufacturing and service industries, and estimate our baseline specification separately on each sub-sample. The results are reported in panel b). The two coefficients are of roughly the same size, but only the one estimated on service industries is statistically significant. This suggests that in an economy such as the UK, which is highly specialized in services, most of the effect of import competition is faced by service workers.

Finally, in panel c) we study heterogeneity across trading partners. In particular, we analyze whether imports from China, which have grown rapidly over the sample period, have different effects compared to imports from other countries. To this purpose, we replace $\Delta I C_{j t-1}$ with two similarly defined variables, corresponding to import competition from China and other countries, respectively. As an instrument for Chinese import competition, we use Chinese exports to the rest of the world (i.e. excluding the UK). The estimated coefficients are positive in both cases, but only the one on import competition from other countries is statistically significant. This coefficient is also much larger than that on Chinese import competition. This result is in line with our previous evidence on manu- 
facturing vs. service workers. In fact, despite its strong increase over the sample period, import competition from China is mostly contained to manufacturing industries, in which the UK is nowadays no longer specialized. Hence, Chinese import competition tends to have a smaller impact on individuals' mental distress as compared to competition from other countries.

\subsection{Mechanisms}

Having shown that import competition has a strong positive effect on individuals' mental distress, we now provide evidence on the mechanisms through which this effect occurs. Our strategy is similar to the one developed by Heckman et al. (2013) for studying how early childhood programs affect adult outcomes. In particular, we adopt a two-stage approach, in which we run OLS regressions of (1) mental distress on proxies for each mechanism and (2) each of these proxies on import competition. If a mechanism is relevant, both regressions will deliver a statistically significant coefficient.

It is widely documented that job switching and income changes have strong implications for mental health (see, e.g., Clark, 2003; McInerney et al., 2013; Farrè et al., 2015). At the same time, several studies show that import competition affects both of these labor market variables (see, in particular, Autor et al., 2013, 2014, 2015b). Following these literatures, we start by analyzing these two channels, which we refer to as 'standard labor market mechanisms'. The results are reported in Table 7. In panel a), we focus on job switching. Specifically, we focus on four mutually exclusive groups of switchers, corresponding to workers who in a given year switch, respectively, to unemployment, other job statuses, ${ }^{7}$ other industries, and other jobs within the same industry. In column (1), we regress GHQ-12 on the four dummy variables capturing each type of switching, plus all controls included in our baseline specification (see column 5 of Table 3). Consistent with previous studies, we find switching out of employment to be strongly positively correlated with mental distress. At the same time, changing industry or job within the same industry

\footnotetext{
${ }^{7}$ Other job statuses include retirement, government training scheme, family care, maternity leave, longterm sickness and disability, and full-time education.
} 
is associated with a reduction in mental distress. In columns (2)-(5), we regress each of the four dummies on $\Delta I C_{j t-1}$ and the whole set of controls. The number of observations drops as we move across columns, since each specification is estimated on a sub-sample of the workers used in the preceding one. For instance, the regression in column (4) uses only the sub-sample of workers who have remained employed, thus excluding those who have switched out of employment. We find little evidence of a correlation between import competition and the likelihood of changing industry or job within the industry. Instead, consistent with previous studies, we find a statistically significant and positive correlation between import competition and the probability of leaving employment. Hence, we have evidence of a first mechanism through which import competition affects mental distress, that is by raising job insecurity, in terms of higher probability of job displacement.

In panel b), we consider the role of wage changes. Column (6) regresses GHQ-12 on the yearly percentage change in each worker's gross wage, along with all the usual controls. Clearly, this regression is only estimated on workers who remain employed for at least two consecutive years, because wages are not observed for those who switch out of employment. We still include in the specification the two dummies for job switching, between and within industries, since wage changes may partly reflect changes in jobs. The results of this regression thus describe the effect of wage growth on mental distress, conditional on job status. Consistent with the existing literature, lower wage growth is strongly associated with higher mental distress also in our sample. As a second step, in column (7) we regress wage growth on $\Delta I C_{j t-1}$ and all the controls used in the previous specification. Similar to previous studies (e.g., Autor et al., 2013, 2014, 2015), we find a significantly negative coefficient on import competition. Hence, we have evidence of a second channel through which import competition operates. That is, for the sub-sample of employed workers, import competition raises mental distress by inducing a smaller increase (or a larger decrease) in earnings.

Next, we ask whether import competition acts through additional, non-standard mechanisms. In particular, consider a continuously employed worker with unchanged wage 
growth. May this worker suffer from import competition? If so, why? A first possible reason is that, even though the directly observable working conditions have remained unchanged, the worker is less satisfied with her job, for instance because this has become more stressful. We investigate this mechanism in Table 8. In columns (1) and (3), we regress GHQ-12 on dummies equal to 1 if the individual declares to be completely satisfied with her job, controlling for wage growth and the dummies for job switching. The two job satisfaction dummies-labeled (a) and (b) - are based on two questions in the BHPS that are essentially identical. While the first question has a larger coverage, the second is accompanied by follow-up questions, which investigate the determinants of job satisfaction and will be used in our subsequent regressions. In both cases, the results show that a reduction in job satisfaction is associated with a significant increase in mental distress. Then, in columns (2) and (4), we regress the job satisfaction variables on import competition and all controls. We find import competition to substantially lower job satisfaction, independent of the proxy we use. Overall, these results shed light on a third mechanism through which import competition worsens mental distress, by decreasing individuals' job satisfaction.

The previous result may reflect different dimensions of job satisfaction. The BHPS asks individuals specific questions about several dimensions, spanning from workload (hours worked) to the use of initiative, job safety, and relation with boss. To study which aspect is more relevant, we have repeated the above estimations replacing the overall job satisfaction variable (b) with dummies equal to 1 if the individual declares to be completely satisfied with a given dimension. We have found that the only aspect that matters is workload. The associated results are reported in columns (5) and (6), which show that import competition makes people less satisfied with their workload, and that this, in turn, is associated with an increase in mental distress. ${ }^{8}$

The latter piece of evidence suggests that import competition makes people more stressed, by inducing firms to switch to longer and more demanding working schedules. In the next columns, we provide additional evidence that this is indeed the case. In columns (7) and

\footnotetext{
${ }^{8}$ Results on the other dimensions of job satisfaction are available upon request.
} 
(8), we use the information on the total number of hours worked and on the number of overtime hours reported in the BHPS. When we regress the yearly percentage change in each variable on import competition, the coefficient is positive and precisely estimated. Hence, import competition implies a statistically significant increase in total hours worked, part of which comes from an increase in overtime hours. As further evidence, in columns (9)-(12) we exploit four BHPS questions on job related stress. Coverage is limited, as these questions were only asked in the year 2004. The dependent variables are dummies taking value 1 if the worker reports being stressed much/most/all of the time, according to four criteria. In particular, the four questions are related to: (1) worrying about job problems after work; (2) finding it difficult to unwind at the end of the day; (3) feeling used up, and (4) feeling exhausted after work. Higher import competition is significantly associated with higher stress according to the first two measures, while for the other two the coefficients are positive but not statistically different from zero. By and large, all these findings hint to a significant role of import competition in increasing pressure on workers, which become more stressed. This has a negative implication for their job satisfaction, and worsens their mental health.

The final mechanism we consider is related to the role of expectations. Indeed, even conditional on current job status, wage growth and job satisfaction, import competition may raise mental distress by worsening expectations about the future, along several dimensions. We exploit three questions about future expectations contained in the BHPS. The first one asks each individual whether she expects a job promotion with her current employer over the next year. The second question is instead about expectations on getting job training over the same period. In both cases, we construct a dummy variable taking value 1 in case of a positive answer. The third question we consider is about financial expectations. Specifically, we use a dummy equal to 1 if the individual expects the next year to be better than the current year in financial terms. In columns (1), (3) and (5) of Table 9, we regress GHQ-12 on each dummy capturing future expectations. We include our controls for job switching, wage growth, and now also for job satisfaction, so that results are condi- 
tional on the level of satisfaction with the current job. We always find better expectations to be associated with lower mental distress. Moreover, when regressing the expectation dummies on import competition, we always obtain negative and significant coefficients (columns (2), (4) and (6)). Such evidence reveals a third mechanism through which import competition worsens mental health. That is, higher import competition is associated to worsened expectations about the future, which in turn are related to higher mental distress.

It is likely that the worsening of job prospects and financial expectations induced by import competition gets reflected in observable changes in individuals' behavior. In particular, individuals may decide to accumulate more savings for precautionary motives and change their consumption behavior accordingly. The BHPS contains information about consumption and saving decisions, which can be used to study how import competition influences individuals' behavior. Specifically, in column (9) we regress the percentage change in monthly savings on import competition and all control variables. The coefficient on import competition is positive and statistically significant, indicating that an increase in import competition does indeed lead individuals to accumulate more savings. Consistent with this result, in column (10) we also find import competition to reduce purchases of durable goods. The dependent variable in this case is the sum of 12 dummies, each taking value 1 if the individual has purchased a given durable good during the year. ${ }^{9}$

To sum up, in this section we have shown that import competition increases individuals' mental distress through four different mechanisms: (1) an increase in the probability of job displacement, (2) lower wage growth, (3) lower job satisfaction, and (4) worsened expectations about the future. How much of the overall effect of import competition on mental distress is mediated through these channels? In order to answer this question, we have estimated a system of equations allowing to simultaneously account for the role of all mediators. In the spirit of the traditional mediation analysis (e.g. Sobel, 1982; Baron and

\footnotetext{
${ }^{9}$ The 12 durable goods considered are: color TV, video recorder, satellite dish, fridge freezer, washing machine, tumble drier, dish washer, microwave oven, home computer, cable TV, compact disc player, telephone. Results on each specific good are also available on request.
} 
Kenny, 1986), this methodology essentially compares the coefficient on import competition in a regression without mediators, to the one obtained in a regression where mediators are added. The dependent variable is GHQ-12 in both cases. Results suggest that the identified mechanisms mediate a non-negligible $26 \%$ of the overall effect of import competition on mental distress.

\section{Conclusion}

We have studied the effect of import competition on mental distress, using a unique data set that combines individual-level information on the mental health of British workers with industry-level information on import competition, for more than 100 industries over 20012007. Our results show that import competition has a strong positive effect on mental distress. A 1 standard deviation increase in import competition in a given industry induces a $1.2 \%$ increase in the mental distress of workers employed in that industry, explaining roughly $13 \%$ of the within-individual standard deviation in mental health. We have also shown that import competition works through several mechanisms. Besides standard labor market channels, whereby import competition raises the probability of job displacement and lowers wage growth, we have documented that import competition also affects continuously employed individuals, by increasing stress on the job and worsening expectations about the future. Overall, our results shed light on a new trade adjustment cost, which is hidden yet economically important. Our findings therefore imply that a proper assessment of the gains from trade needs to take account of the cost that import competition may impose on individuals by lowering their subjective well-being. 


\section{References}

[1] Acemoglu, D., D. Autor, D. Dorn, G. Hanson and B. Price, 2015, 'Import Competition and the Great U.S. Employment Sag of the 2000s,' Journal of Labor Economics, forthcoming.

[2] Adda, J. and Y. Fawaz, 2015, 'Trade-Induced Mortality,' Mimeo, Bocconi University.

[3] Artis, M., M. Marcellino and T. Proietti, 2005, 'Dating the Euro Area Business Cycle,' in Reichlin, L. (ed.), The Euro Area Business Cycle: Stylized Facts and Measurement Issues, CEPR.

[4] Autor, D., D. Dorn and G. Hanson, 2013, 'The China Syndrome: Local Labor Market Effects of Import Competition in the United States,' American Economic Review, 103, pp. 2121-2168.

[5] Autor, D., D. Dorn and G. Hanson, 2014, 'Trade Adjustment: Worker Level Evidence,' Quarterly Journal of Economics, 129, pp. 1799-1860.

[6] Autor, D., D. Dorn and G. Hanson, 2015a, 'The China Shock: Learning from Labor Market Adjustment to Large Changes in Trade,' Mimeo, University of Zurich.

[7] Autor, D., D. Dorn and G. Hanson, 2015b, 'Untangling Trade and Technology: Evidence from Local Labor Markets,' Economic Journal, 125, pp. 621-646.

[8] Baron, R.M. and D.A. Kenny, 1986, 'The moderator-mediator variable distinction in social psychological research: Conceptual, strategic, and statistical considerations,' Journal of Personality and Social Psychology, 51, pp. 1173-1182.

[9] Bernard, A., J. Jensen and P. Schott, 2006, 'Survival of the Best Fit: Exposure to LowWage Countries and the (Uneven) Growth of U.S. Manufacturing Plants,' Journal of International Economics, 68, pp. 219-237.

[10] Clark, A., 2003, 'Unemployment as a Social Norm: Psychological Evidence from Panel Data,' Journal of Labor Economics, 21, pp. 323-351. 
[11] Colantone, I. and R. Crinò, 2014, 'New Imported Inputs, New Domestic Products,' Journal of International Economics, 92, pp. 147-165.

[12] Connolly, M., 2013, 'Some Like It Mild and Not Too Wet: The Influence of Weather on Subjective Well-Being,' Journal of Happines Studies, 14, pp. 457-473.

[13] Cooper, C. and P. Dewe, 2008, 'Well-Being - Absenteeism, Presenteeism, Costs and Challenges,' Occupational Medicine, 58, pp. 522-524.

[14] Cornaglia, F., A. Leigh and N. Feldman, 'Crime and Mental Wellbeing,' Journal of Human Resources, 49, pp. 110-140.

[15] Crinò, R. and P. Epifani, 2014a, 'The Skill Bias of the U.S. Trade Deficit,' CEPR Discussion Paper 9899.

[16] Crinò, R. and P. Epifani, 2014b, 'Trade Imbalances, Export Structure and Wage Inequality,' Economic Journal, 124, pp. 507-539.

[17] Dauth, W., S. Findeisen and J. Suedekum, 2014, 'The Rise of the East and the Far East: German Labor Markets and Trade Integration,' Journal of the European Economic Association, 12, pp. 1643-1675.

[18] Di Tella, R., S. Galiani and E. Schargrodsky, 2007, 'The Formation of Beliefs: Evidence from the Allocation of Land Titles to Squatters,' Quarterly Journal of Economics, 122, pp. 209-241.

[19] Dustmann, C. and F. Fasani, 2015, 'The Effect of Local Area Crime on Mental Health,' Economic Journal, forthcoming.

[20] Farrè, L., F. Fasani and H. Mueller, 2015, 'Feeling Useless: The Effect of Unemployment on Mental Health in the Great Recession,' IZA Discussion Paper 9235.

[21] Goldberg, D., 1978, Manual of the General Health Questionnaire, Windsor: National Foundation. 
[22] Goldberg, P., A. Khandelwal, N. Pavcnik and P. Topalova, 2010, 'Imported Intermediate Inputs and Domestic Product Growth: Evidence from India,' Quarterly Journal of Economics, 125, pp. 1727-1767.

[23] Hallet, A.H. and C. Richter, 2006, 'Is the Convergence of Business Cycles a Global or Regional Issue? The UK, US and Euroland,' International Journal of Finance and Economics, 11, pp. 177-194.

[24] Heckman, J., R. Pinto and P. Savelyev, 2013, 'Understanding the Mechanisms through Which an Influential Early Childhood Program Boosted Adult Outcomes,' American Economic Review 103, pp. 2052-2086.

[25] Katz, K., J. Kling and J. Liebman, 2001, 'Moving to Opportunity in Boston: Early Results of a Randomized Mobility Experiment,' Quarterly Journal of Economics, 116, pp. 607654.

[26] Khandelwal, A.K., 2010, 'The Long and Short (of) Quality Ladders,' Review of Economic Studies, 77, pp. 1450-1476.

[27] Kling J., J. Liebman and L. Katz, 2007, 'Experimental Analysis of Neighbourhood Effects,' Econometrica, 75, pp. 83-119.

[28] Levine, D. and D. Rothman, 2006, 'Doea Trade Affect Child Health', Journal of Health Economics, 25, pp. 538-554.

[29] Ludwig J., G. Duncan, L. Gennetian, L. Katz, R. Kessler, J. Kling and L. Sanbonmatsu, 2012, 'Neighborhood Effects on the Long-Term Well-Being of Low-Income Adults,' Science, 21, 337, pp. 1505-1510.

[30] Marcus, J., 2013, 'The Effect of Unemployment on the Mental Health of Spouses - Evidence from Plant Closures in Germany,' Journal of Health Economics, 32, pp. 546-558.

[31] McInerney, M., J. Mellor and L. Nicholas, 2013, 'Recession Depression: Mental Health Effects of the 2008 Stock Market Crash,' Journal of Health Economics, 32, pp. 1090-1104. 
[32] McCrone, P., S. Dhanasiri, A. Patel, M. Knapp and S. Lawton-Smith, 2008, Paying the Price: The Cost of Mental Health Care in England to 2026, King's Fund.

[33] Oster, E., 2012, 'Routes of Infection: Exports and HIV Incidence in Sub-Saharan Africa,' Journal of the European Economic Association, 10, pp. 1025-1058.

[34] Owen, A. and S. Wu, 2007, 'Is Trade Good for Your Health,' Review of International Economics, 15, pp. 660-682.

[35] Ruhm, C., 2000, 'Are Recessions Good for Your Health?,' Quarterly Journal of Economics, 115, pp. 617-650.

[36] Schwandt, H., 2014, 'Wealth Shocks and Health Outcomes: Evidence from Stock Market Fluctuations,' CEP Discussion Paper 1281.

[37] Smith, J., 1999, 'Healthy Bodies and Thick Wallets: The Dual Relation between Health and Economic Status,' Journal of Economic Perspectives, 13, pp. 145-166.

[38] Sobel, M.E., 1982, 'Asymptotic Confidence Intervals for Indirect Effects in Structural Equation Models,' Sociological Methodology, 13, pp. 290-312.

[39] Sullivan, D. and T. von Wachter, 2009, 'Job Displacement and Mortality: An Analysis Using Administrative Data,' Quarterly Journal of Economics, 124, pp. 1265-1306. 
Table 1 - Descriptive Statistics on the Individual-Level Variables

\begin{tabular}{|c|c|c|c|c|c|c|c|c|}
\hline & Mean & $\begin{array}{l}\text { Overall } \\
\text { Std. Dev. }\end{array}$ & $\begin{array}{c}\text { Within-Individual } \\
\text { Std. Dev. }\end{array}$ & Obs. & & Mean & $\begin{array}{c}\text { Overall } \\
\text { Std. Dev. }\end{array}$ & $\overline{\text { Obs. }}$ \\
\hline GHQ-12 (Likert score) & 30.0 & 14.2 & 9.6 & 52781 & Never married & 17.0 & 37.5 & 52753 \\
\hline GHQ 1 (Anxiety and depression) & 30.8 & 20.1 & 13.0 & 52781 & Self-employed & 10.9 & 31.2 & 52779 \\
\hline GHQ 2 (Social dysfunction) & 33.9 & 12.7 & 9.5 & 52781 & Employed & 82.2 & 38.2 & 52779 \\
\hline GHQ 3 (Loss of confidence) & 17.1 & 20.8 & 13.1 & 52781 & Unemployed & 1.7 & 12.9 & 52779 \\
\hline GHQ-12 (Caseness score) & 13.8 & 23.6 & 16.6 & 52781 & Retired & 1.6 & 12.4 & 52779 \\
\hline Physical health & 7.8 & 9.9 & - & 52781 & Maternity leave & 0.8 & 8.8 & 52779 \\
\hline Age & 41.1 & 12.2 & - & 52778 & Family care & 1.1 & 10.6 & 52779 \\
\hline Male & 50.3 & 50.0 & - & 52781 & FT student, school & 0.7 & 8.5 & 52779 \\
\hline Higher degree & 4.1 & 19.8 & - & 51805 & LT sick, disabled & 0.6 & 7.6 & 52779 \\
\hline First degree & 15.0 & 35.7 & - & 51805 & GVT training scheme & 0.1 & 2.6 & 52779 \\
\hline Teaching QF & 2.3 & 15.0 & - & 51805 & Other job status & 0.3 & 5.5 & 52779 \\
\hline Other higher QF & 31.4 & 46.4 & - & 51805 & Household size & 3.0 & 1.3 & 52781 \\
\hline Nursing QF & 0.9 & 9.6 & - & 51805 & Single non-elderly & 8.4 & 27.8 & 52781 \\
\hline GCE A levels & 12.5 & 33.1 & - & 51805 & Single elderly & 0.8 & 9.0 & 52781 \\
\hline GCE $O$ levels or equivalent & 17.2 & 37.7 & - & 51805 & Couple, no children & 27.4 & 44.6 & 52781 \\
\hline Commercial QF, no O levels & 1.7 & 12.8 & - & 51805 & Couple, dep. children & 37.7 & 48.5 & 52781 \\
\hline CSE grade $2-5$, scot grade $4-5$ & 3.3 & 17.9 & - & 51805 & Couple, non-dep. children & 14.9 & 35.6 & 52781 \\
\hline Apprenticeship & 1.0 & 9.9 & - & 51805 & Lone parent, dep. children & 4.3 & 20.3 & 52781 \\
\hline Other QF & 0.5 & 6.8 & - & 51805 & Lone parent, non-dep. children & 3.7 & 18.9 & 52781 \\
\hline No QF & 10.0 & 30.0 & - & 51805 & $2+$ unrelated adults & 1.4 & 11.9 & 52781 \\
\hline Still at school, no QF & 0.2 & 4.2 & - & 51805 & Other households & 1.4 & 11.6 & 52781 \\
\hline Married & 59.5 & 49.1 & - & 52753 & Owned house or on mortgage & 82.7 & 37.8 & 52549 \\
\hline Leaving as couple & 14.7 & 35.4 & - & 52753 & Shared house ownership & 0.4 & 6.5 & 52549 \\
\hline Widowed & 1.3 & 11.4 & - & 52753 & Rented house & 15.6 & 36.2 & 52549 \\
\hline Divorced & 5.5 & 22.9 & - & 52753 & Rent-free house & 1.0 & 10.1 & 52549 \\
\hline Separated & 2.0 & 13.9 & - & 52753 & Other house types & 0.3 & 5.1 & 52549 \\
\hline
\end{tabular}


Table 2 - Descriptive Statistics on Import Competition

Industries with lowest import competition shock

Manufacture of steam generators, exc. central heating hot water boilers

Production of salt

Electricity, gas and water supply

Water transport

Manufacture of wooden containers

Industries with highest in import competition shock

Manufacture of pesticides and other agro-chemical products 51.6

Manufacture of prepared animal feeds $\quad 55.5$

$\begin{array}{ll}\text { Manufacture of refined petroleoum products } & 72.9\end{array}$

$\begin{array}{ll}\text { Manufacture of television, radio transmitters and phone apparatus } & 82.8\end{array}$

Mining and agglomeration of hard coal 87.3

The table reports industry-level averages of $\Delta I C$ over the period 2001-2007. 
Table 3 - Baseline Estimates

\begin{tabular}{|c|c|c|c|c|c|}
\hline & $(1)$ & (2) & (3) & (4) & (5) \\
\hline \multirow[t]{2}{*}{$\Delta \mathrm{IC}$} & $0.217^{* * *}$ & $0.493 * *$ & $0.920^{* *}$ & $0.729 * *$ & $1.201^{* * *}$ \\
\hline & {$[0.077]$} & {$[0.221]$} & {$[0.455]$} & {$[0.335]$} & {$[0.436]$} \\
\hline Estimator & OLS & 2SLS & 2SLS & 2SLS & 2SLS \\
\hline Individual controls & no & no & yes & yes & yes \\
\hline Household controls & no & no & yes & yes & yes \\
\hline Industry controls & no & no & no & no & yes \\
\hline Individual effects & yes & yes & yes & yes & yes \\
\hline Industry effects & no & no & no & yes & yes \\
\hline Year effects & no & no & no & yes & yes \\
\hline Obs. & 52781 & 50154 & 48510 & 48510 & 44043 \\
\hline R2 & 0.55 & 0.52 & 0.52 & 0.53 & 0.53 \\
\hline \multicolumn{6}{|l|}{ First-stage results } \\
\hline \multirow[t]{2}{*}{$\Delta$ World Exp. } & - & $0.310^{* * *}$ & $0.160^{* * *}$ & $0.250^{* * *}$ & $0.206^{* * *}$ \\
\hline & - & {$[0.007]$} & {$[0.008]$} & {$[0.007]$} & {$[0.007]$} \\
\hline Kleibergen-Paap F-Statistic & - & 1907.1 & 438.2 & 1278.7 & 881.0 \\
\hline \multicolumn{6}{|c|}{$\begin{array}{l}\text { The dependent variable is } G H Q-12 \text {, normalized between } 0 \text { and } 100 . \Delta I C \text { is the } 5 \text {-year } \% \text { change in import competition (the } \\
\text { ratio of imports over apparent consumption) in the industry in which a given worker was employed during the previous year. } \\
\text { Individual controls include: log age and its square, physical health, and dummies for education level, marital status and job } \\
\text { status. Household controls include: household size and dummies for household type and home ownership. Industry controls } \\
\text { include the } 5 \text {-year } \% \text { change in real output, output price, employment share of high-skill workers, value added, and export } \\
\text { intensity. All controls refer to the year } t-1 \text {; continuous variables are normalized by their standard deviation. } \Delta W \text { orld Exp. is the } \\
5 \text {-year } \% \text { change in non-UK exports to the rest of the world, defined for each worker's past industry of employment. Standard } \\
\text { errors are corrected for clustering within individuals. } * * *, * * *=\text { indicate significance at the } 1,5 \text { and } 10 \% \text { level, respectively. }\end{array}$} \\
\hline
\end{tabular}




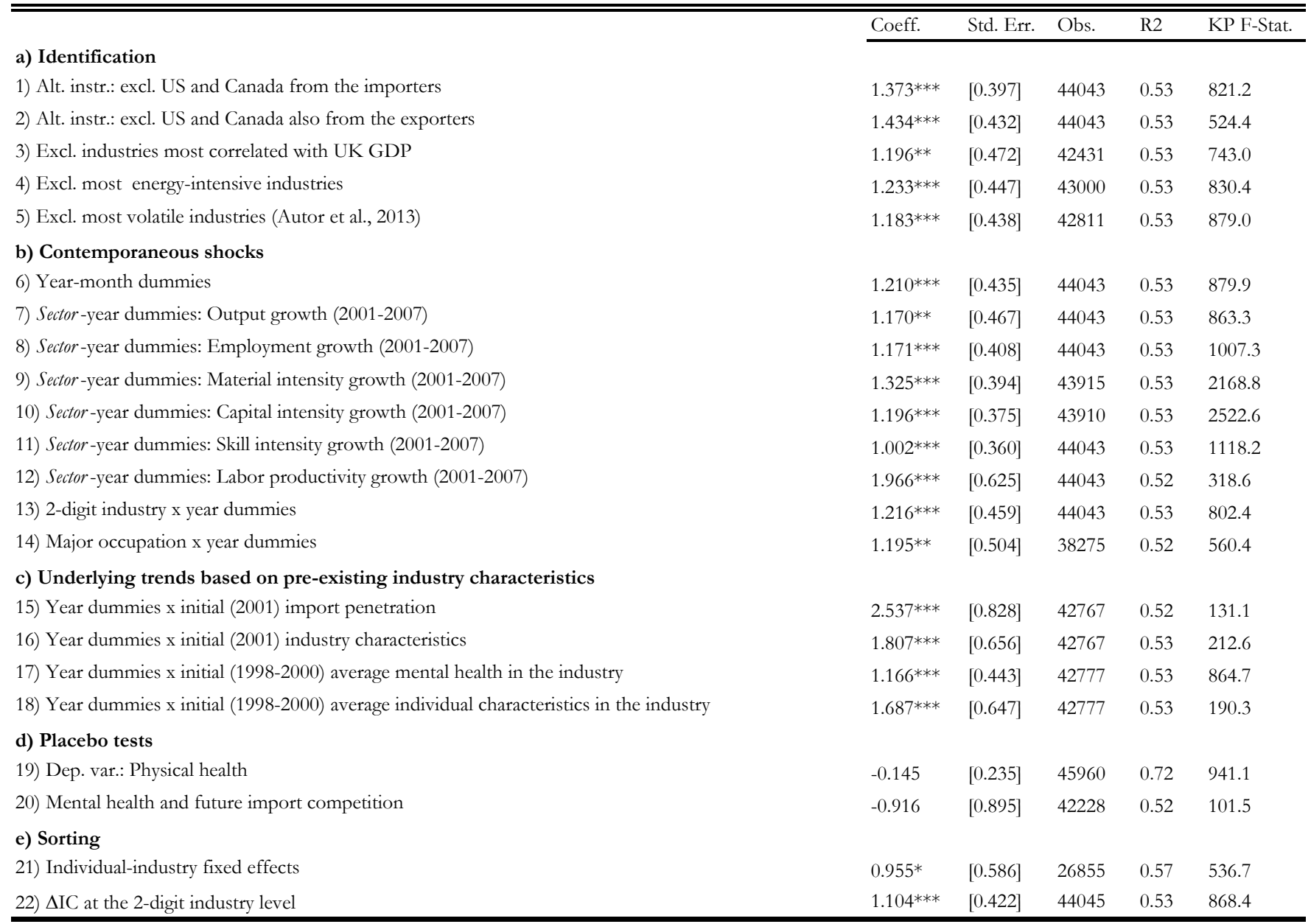

The dependent variable is $G H Q-12$. Coefficients refer to the explanatory variable $\triangle I C$. All regressions include the same controls as in column (5) of Table 3 and are estimated by 2 SLS. Standard errors are corrected for clustering within individuals. $* * *, * *, *=$ indicate significance at the 1,5 and $10 \%$ level, respectively. 


\begin{tabular}{|c|c|c|c|c|c|}
\hline & Coeff. & Std. Err. & Obs. & $\overline{\mathrm{R} 2}$ & "KP F-Stat. \\
\hline 1) GHQ-12 (Caseness score) & $1.390^{*}$ & {$[0.774]$} & 44043 & 0.48 & 881.0 \\
\hline 2) GHQ 1 (Anxiety and depression) & $1.193^{* *}$ & {$[0.607]$} & 44043 & 0.56 & 881.0 \\
\hline 3) GHQ 2 (Social dysfunction) & $1.345^{* * *}$ & {$[0.424]$} & 44043 & 0.41 & 881.0 \\
\hline 4) GHQ 3 (Loss of confidence) & 0.787 & {$[0.580]$} & 44043 & 0.58 & 881.0 \\
\hline 5) GHQ-12 (Have you been able to concentrate on whatever you're doing?) & $1.432 * *$ & {$[0.580]$} & 44043 & 0.35 & 881.0 \\
\hline 6) GHQ-12 (Have you lost much sleep over worry?) & 0.572 & {$[0.780]$} & 44043 & 0.50 & 881.0 \\
\hline 7) GHQ-12 (Have you felt that you were playing a useful part in things?) & $1.139 *$ & {$[0.587]$} & 44043 & 0.36 & 881.0 \\
\hline 8) GHQ-12 (Have you felt capable of making decisions about things?) & $1.338 * *$ & {$[0.549]$} & 44043 & 0.37 & 881.0 \\
\hline 9) GHQ-12 (Have you felt constantly under strain?) & 0.979 & {$[0.759]$} & 44043 & 0.49 & 881.0 \\
\hline 10) GHQ-12 (Have you felt you couldn't overcome your difficulties?) & 0.624 & {$[0.710]$} & 44043 & 0.48 & 881.0 \\
\hline 11) GHQ-12 (Have you been able to enjoy your normal day-to-day activities?) & $1.142^{*}$ & {$[0.621]$} & 44043 & 0.35 & 881.0 \\
\hline 12) GHQ-12 (Have you been able to face up to problems?) & $1.256^{* *}$ & {$[0.511]$} & 44043 & 0.36 & 881.0 \\
\hline 13) GHQ-12 (Have you been feeling unhappy or depressed?) & $2.598 * * *$ & {$[0.852]$} & 44043 & 0.49 & 881.0 \\
\hline 14) GHQ-12 (Have you been losing confidence in yourself?) & 0.432 & {$[0.709]$} & 44043 & 0.54 & 881.0 \\
\hline 15) GHQ-12 (Have you been thinking of yourself as a worthless person?) & $1.143^{*}$ & {$[0.610]$} & 44043 & 0.55 & 881.0 \\
\hline 16) GHQ-12 (Have you been feeling reasonably happy, all things considered?) & $1.763^{* * *}$ & {$[0.673]$} & 44043 & 0.37 & 881.0 \\
\hline
\end{tabular}




\begin{tabular}{|c|c|c|c|c|c|c|c|c|c|c|}
\hline & \multicolumn{7}{|c|}{$\begin{array}{l}\text { a) Individual } \\
\text { Characteristics }\end{array}$} & \multicolumn{2}{|c|}{$\begin{array}{l}\text { b) Manufacturing vs. } \\
\text { Services }\end{array}$} & \multirow{2}{*}{$\begin{array}{c}\text { c) China vs. } \\
\text { Other Countries } \\
(10) \\
\end{array}$} \\
\hline & $(1)$ & $(2)$ & (3) & $(4)$ & $(5)$ & $(6)$ & $(7)$ & $(8)$ & $(9)$ & \\
\hline$\Delta \mathrm{IC}$ & $\begin{array}{l}1.152^{* *} \\
{[0.521]}\end{array}$ & $\begin{array}{l}1.281 * * * \\
{[0.440]}\end{array}$ & $\begin{array}{l}1.348^{* * *} \\
{[0.458]}\end{array}$ & $\begin{array}{l}1.390^{* * *} \\
{[0.474]}\end{array}$ & $\begin{array}{l}1,087 \\
{[0.728]}\end{array}$ & $\begin{array}{l}1.228^{*} \\
{[0.633]}\end{array}$ & $\begin{array}{l}1.095 \\
{[0.872]}\end{array}$ & & & \\
\hline$\Delta \mathrm{IC} *$ Male & $\begin{array}{l}0.088 \\
{[0.477]}\end{array}$ & & & & & & $\begin{array}{l}0.080 \\
{[0.518]}\end{array}$ & & & \\
\hline$\Delta \mathrm{IC} *$ Self-employed & & $\begin{array}{l}-1.575 \\
{[1.023]}\end{array}$ & & & & & $\begin{array}{l}-5.859 * * \\
{[2.465]}\end{array}$ & & & \\
\hline$\Delta \mathrm{IC} *$ Over 50 & & & $\begin{array}{l}-0.530 \\
{[0.570]}\end{array}$ & & & & $\begin{array}{l}-0.406 \\
{[0.582]}\end{array}$ & & & \\
\hline$\Delta \mathrm{IC} *$ Long tenure & & & & $\begin{array}{l}-0.953 \\
{[0.586]}\end{array}$ & & & $\begin{array}{l}-0.942 \\
{[0.599]}\end{array}$ & & & \\
\hline$\Delta \mathrm{IC} *$ Permanent & & & & & $\begin{array}{l}0.062 \\
{[0.706]}\end{array}$ & & $\begin{array}{l}0.431 \\
{[0.801]}\end{array}$ & & & \\
\hline$\Delta \mathrm{IC} *$ Full Time & & & & & & $\begin{array}{l}-0.148 \\
{[0.556]}\end{array}$ & $\begin{array}{l}-0.227 \\
{[0.609]}\end{array}$ & & & \\
\hline Dummy over 50 & & & $\begin{array}{l}0.317 \\
{[0.497]}\end{array}$ & & & & $\begin{array}{l}0.496 \\
{[0.529]}\end{array}$ & & & \\
\hline Dummy long tenure & & & & $\begin{array}{l}1.328^{* * *} \\
{[0.362]}\end{array}$ & & & $\begin{array}{l}1.294 * * * \\
{[0.368]}\end{array}$ & & & \\
\hline Dummy permanent & & & & & $\begin{array}{l}1.346 * * * \\
{[0.475]}\end{array}$ & & $\begin{array}{l}1.177 * * \\
{[0.531]}\end{array}$ & & & \\
\hline Dummy full time & & & & & & $\begin{array}{l}0.846^{* *} \\
{[0.397]}\end{array}$ & $\begin{array}{l}0.757^{*} \\
{[0.450]}\end{array}$ & & & \\
\hline$\Delta \mathrm{IC}$ (Manufacturing sub-sample) & & & & & & & & $\begin{array}{l}1.473 \\
{[1.009]}\end{array}$ & & \\
\hline$\Delta \mathrm{IC}$ (Services sub-sample) & & & & & & & & & $\begin{array}{l}1.228^{* *} \\
{[0.483]}\end{array}$ & \\
\hline$\Delta \mathrm{IC}$ from China & & & & & & & & & & $\begin{array}{l}0.419 \\
{[0.270]}\end{array}$ \\
\hline$\Delta \mathrm{IC}$ from other countries & & & & & & & & & & $\begin{array}{l}1.440^{* * *} \\
{[0.368]}\end{array}$ \\
\hline Obs. & 44043 & 44043 & 44042 & 38294 & 44041 & 43674 & 38061 & 6129 & 37097 & 33075 \\
\hline $\mathrm{R} 2$ & 0.53 & 0.53 & 0.53 & 0.53 & 0.53 & 0.53 & 0.53 & 0.59 & 0.52 & 0.54 \\
\hline Kleibergen-Paap F-Statistic & 362.91 & 127.75 & 258.46 & 456.18 & 413.24 & 279.33 & 67.70 & 228.63 & 729.69 & 810.12 \\
\hline
\end{tabular}


Table 7 - Mechanisms: Job Switching and Wage Growth

\begin{tabular}{|c|c|c|c|c|c|c|c|}
\hline & \multicolumn{5}{|c|}{ a) Job switching } & \multicolumn{2}{|c|}{ b) Wage growth } \\
\hline & $(1)$ & $(2)$ & (3) & (4) & (5) & (6) & (7) \\
\hline & \multirow[b]{2}{*}{ GHQ-12 } & \multicolumn{4}{|c|}{ Dummy for switching to: } & \multirow[b]{2}{*}{ GHQ-12 } & \multirow[b]{2}{*}{ Wage growth } \\
\hline & & Unemployment & Other job status & Other industry & Other job & & \\
\hline \multirow[t]{2}{*}{ Switch to unemployment } & $6.599 * * *$ & & & & & - & - \\
\hline & {$[0.413]$} & & & & & - & - \\
\hline \multirow[t]{2}{*}{ Switch to other job statuses } & $0.929^{* * *}$ & & & & & - & - \\
\hline & {$[0.233]$} & & & & & - & - \\
\hline \multirow[t]{2}{*}{ Switch to a different industry } & $-1.003 * * *$ & & & & & $-0.894 * * *$ & 0.005 \\
\hline & {$[0.100]$} & & & & & {$[0.078]$} & {$[0.005]$} \\
\hline \multirow[t]{2}{*}{ Switch to another job in the same industry } & $-0.296 * * *$ & & & & & $-0.243 * *$ & $0.013 * * *$ \\
\hline & {$[0.095]$} & & & & & {$[0.097]$} & {$[0.002]$} \\
\hline \multirow[t]{2}{*}{ Wage growth } & & & & & & $-0.814^{* * *}$ & \\
\hline & & & & & & {$[0.057]$} & \\
\hline \multirow[t]{2}{*}{$\Delta \mathrm{IC}$} & & 0.000 & $0.002^{* * *}$ & 0.002 & 0.003 & & $-0.003 * * *$ \\
\hline & & {$[0.001]$} & {$[0.001]$} & {$[0.004]$} & {$[0.004]$} & & {$[0.001]$} \\
\hline Obs. & 45986 & 53195 & 52320 & 49173 & 32809 & 36121 & 36434 \\
\hline R2 & 0.56 & 0.46 & 0.47 & 0.48 & 0.49 & 0.56 & 0.25 \\
\hline
\end{tabular}

The dependent variables are indicated in columns' headings. All regressions include the same controls as in column (5) of Table 3 and are estimated by OLS. ${ }^{* * *}, * *, *=$ indicate significance at the 1,5 and $10 \%$ level, respectively. 


\begin{tabular}{|c|c|c|c|c|c|c|c|c|c|c|c|c|}
\hline & (1) & (2) & (3) & $(4)$ & (5) & (6) & $(7)$ & (8) & (9) & $(10)$ & $(11)$ & (12) \\
\hline & GHQ-12 & Job Sat Overall (a) & GHQ-12 & Job Sat Overall (b) & GHQ-12 & Job Sat Hours & Change in Tot Hours & Change in Over Hours & Worry About Job & Difficult to Unwind & Feel Used Up & Feel Exhausted \\
\hline \multirow[t]{2}{*}{ Switch to unemployment } & - & - & - & - & - & - & - & - & - & - & - & - \\
\hline & - & - & - & - & - & - & - & - & - & - & - & - \\
\hline \multirow[t]{2}{*}{ Switch to other job statuses } & - & - & - & - & - & - & - & - & - & - & - & - \\
\hline & - & - & - & - & - & - & - & - & - & - & - & - \\
\hline \multirow[t]{2}{*}{ Switch to a different } & $-0.636^{* * *}$ & $0.058^{* * *}$ & $-1.179 * * *$ & $0.062 * * *$ & $-1.682^{* * *}$ & $0.031 * * *$ & $0.103 * *$ & 0.118 & -0.005 & $-0.031 * * *$ & $-0.033^{* * *}$ & $-0.041 * * *$ \\
\hline & {$[0.111]$} & {$[0.006]$} & {$[0.383]$} & {$[0.009]$} & {$[0.267]$} & {$[0.010]$} & {$[0.046]$} & {$[0.119]$} & {$[0.005]$} & {$[0.006]$} & {$[0.007]$} & {$[0.007]$} \\
\hline \multirow[t]{2}{*}{ Switch other job same ind. } & $-0.267 * *$ & $0.020^{* * *}$ & -0.257 & $0.028^{* *}$ & $-1.048^{* * *}$ & $0.012^{*}$ & 0.024 & 0.010 & -0.004 & 0.002 & -0.014 & $-0.025^{* * *}$ \\
\hline & {$[0.112]$} & {$[0.005]$} & {$[0.810]$} & {$[0.011]$} & {$[0.171]$} & {$[0.006]$} & {$[0.024]$} & {$[0.033]$} & {$[0.003]$} & {$[0.005]$} & {$[0.009]$} & {$[0.006]$} \\
\hline \multirow[t]{2}{*}{ Wage growth } & $-0.520^{* * *}$ & $0.043^{* * *}$ & -0.215 & $0.049 * * *$ & 0.207 & $-0.020^{* * *}$ & $1.418^{* * *}$ & $1.087^{* * *}$ & 0.003 & $0.017^{* * *}$ & $0.027^{* * *}$ & $0.014^{* * *}$ \\
\hline & {$[0.080]$} & {$[0.003]$} & {$[0.408]$} & {$[0.005]$} & {$[0.243]$} & {$[0.004]$} & {$[0.162]$} & {$[0.144]$} & {$[0.008]$} & {$[0.004]$} & {$[0.005]$} & {$[0.004]$} \\
\hline \multirow[t]{2}{*}{ Job sat overall (a) } & $-6.784 * * *$ & & & & & & & & & & & \\
\hline & {$[0.178]$} & & & & & & & & & & & \\
\hline \multirow[t]{2}{*}{ Job sat overall (b) } & & & $-7.415^{* * *}$ & & & & & & & & & \\
\hline & & & {$[0.421]$} & & & & & & & & & \\
\hline \multirow[t]{2}{*}{ Job sat hours } & & & & & $-4.730^{* * *}$ & & & & & & & \\
\hline & & & & & {$[0.264]$} & & & & & & & \\
\hline \multirow[t]{2}{*}{$\Delta \mathrm{IC}$} & & $-0.008^{* * *}$ & & $-0.014^{* * *}$ & & $-0.006^{* * *}$ & $0.065^{* * *}$ & $0.026^{*}$ & $0.172^{* *}$ & $0.081 * * *$ & 0.046 & 0.066 \\
\hline & & {$[0.001]$} & & {$[0.004]$} & & {$[0.002]$} & {$[0.014]$} & {$[0.014]$} & {$[0.074]$} & {$[0.026]$} & {$[0.064]$} & {$[0.059]$} \\
\hline Obs. & 30467 & 30467 & 6773 & 6849 & 8688 & 8767 & 33054 & 34972 & 5162 & 5162 & 5159 & 5160 \\
\hline R2 & 0.60 & 0.53 & 0.80 & 0.90 & 0.77 & 0.88 & 0.28 & 0.19 & 0.05 & 0.05 & 0.05 & 0.05 \\
\hline
\end{tabular}

The dependent variables are indicated in columns' headings. All regressions include the same controls as in column (5) of Table 3 and are estimated by OLS. $*^{* *}, * *, *=$ indicate significance at the 1,5 and $10 \%$ level, respectively. 


\begin{tabular}{|c|c|c|c|c|c|c|c|c|}
\hline & $(1)$ & (2) & (3) & (4) & $(5)$ & $(6)$ & (7) & $(8)$ \\
\hline \multirow{3}{*}{ Switch to unemployment } & GHQ-12 & Exp. Job Prom. & GHQ-12 & Exp. Train. on Job & GHQ-12 & Exp. Financial & Change in Savings & Purchase of Durables \\
\hline & - & - & - & - & - & - & - & - \\
\hline & - & - & - & - & - & - & - & - \\
\hline \multirow[t]{2}{*}{ Switch to other job statuses } & - & - & - & - & - & - & - & - \\
\hline & - & - & - & - & - & - & - & - \\
\hline \multirow[t]{2}{*}{ Switch to a different industry } & $-0.696^{* * *}$ & $0.018^{* * *}$ & $-0.716^{* * *}$ & $0.028 * * *$ & $-0.568^{* * *}$ & $0.032 * * *$ & 0.028 & -0.084 \\
\hline & {$[0.147]$} & {$[0.004]$} & {$[0.127]$} & {$[0.006]$} & {$[0.115]$} & {$[0.006]$} & {$[0.028]$} & {$[0.139]$} \\
\hline \multirow[t]{2}{*}{ Switch other job same ind. } & $-0.297 * *$ & -0.003 & $-0.288 * * *$ & $0.022 * * *$ & $-0.301 * *$ & 0.004 & $0.033^{* *}$ & 0.174 \\
\hline & {$[0.114]$} & {$[0.004]$} & {$[0.104]$} & {$[0.002]$} & {$[0.115]$} & {$[0.009]$} & {$[0.013]$} & {$[0.107]$} \\
\hline \multirow[t]{2}{*}{ Wage growth } & $-0.454 * * *$ & 0.000 & $-0.465^{* * *}$ & $0.018^{* * *}$ & $-0.544 * * *$ & $-0.014^{*}$ & $0.195^{* * *}$ & $0.234^{*}$ \\
\hline & {$[0.092]$} & {$[0.003]$} & {$[0.096]$} & {$[0.004]$} & {$[0.073]$} & {$[0.007]$} & {$[0.010]$} & {$[0.126]$} \\
\hline \multirow[t]{2}{*}{ Job sat overall (a) } & $-6.673^{* * *}$ & $0.049 * * *$ & $-6.671 * * *$ & $0.059 * * *$ & $-6.682^{* * *}$ & $0.007 *$ & $0.024 * *$ & 0.037 \\
\hline & [0.199] & {$[0.004]$} & {$[0.186]$} & {$[0.004]$} & {$[0.154]$} & {$[0.004]$} & {$[0.012]$} & {$[0.127]$} \\
\hline \multirow[t]{2}{*}{ Expectations: job promotion } & $-0.850 * * *$ & & & & & & & \\
\hline & {$[0.186]$} & & & & & & & \\
\hline \multirow[t]{2}{*}{ Expectations: training on job } & & & $-0.362 * * *$ & & & & & \\
\hline & & & {$[0.083]$} & & & & & \\
\hline \multirow[t]{2}{*}{ Expectations: financial } & & & & & $-0.274 * * *$ & & & \\
\hline & & & & & {$[0.088]$} & & & \\
\hline \multirow[t]{2}{*}{$\Delta \mathrm{IC}$} & & $-0.003 * * *$ & & $-0.004 * *$ & & $-0.004 * *$ & $0.036 * * *$ & $-0.146^{* * *}$ \\
\hline & & {$[0.001]$} & & {$[0.001]$} & & {$[0.002]$} & {$[0.007]$} & {$[0.041]$} \\
\hline Obs. & 28945 & 28945 & 29451 & 29451 & 29625 & 29625 & 10838 & 30306 \\
\hline $\mathrm{R} 2$ & 0.61 & 0.50 & 0.60 & 0.58 & 0.60 & 0.50 & 0.34 & 0.39 \\
\hline
\end{tabular}

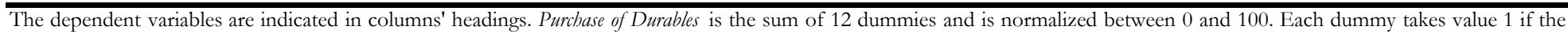

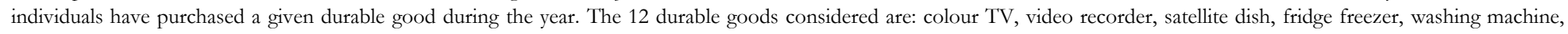

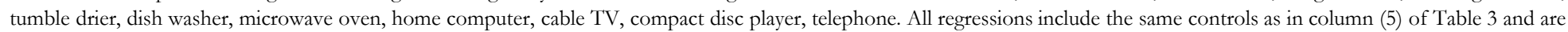
estimated by OLS. $* * *, * *, *=$ indicate significance at the 1,5 and $10 \%$ level, respectively. 
Figure 1 - Distribution of the Import Competition Shock across Industries

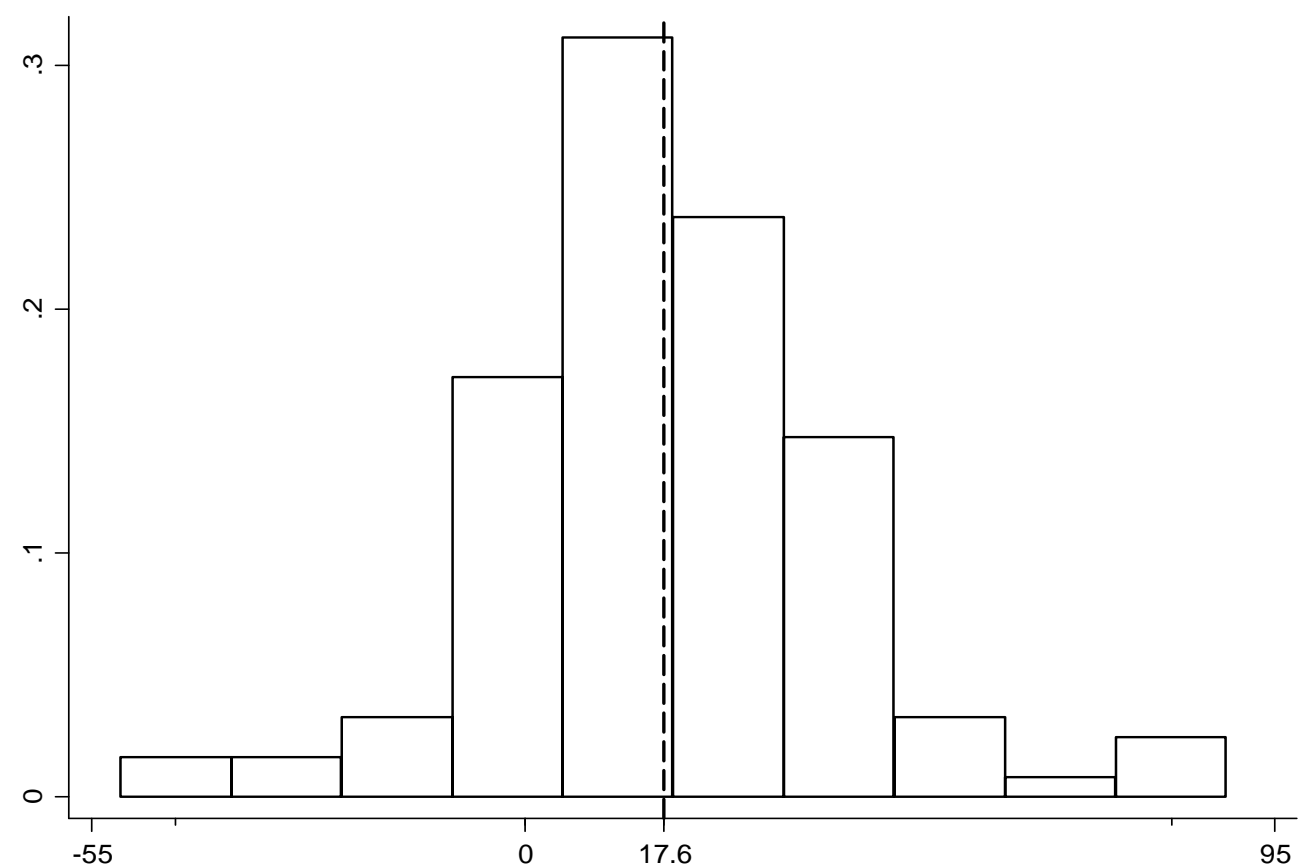

The figure reports industry-level averages of $\Delta I C$ over the period 2001-2007. 
Table A1 - GHQ Questions and Answers

\begin{tabular}{|c|c|}
\hline GHQ Index & Question \\
\hline \multirow{3}{*}{ GHQ 1: Anxiety and depression } & Have you recently: \\
\hline & 1) lost much sleep over worry? \\
\hline & 2) felt constantly under strain? \\
\hline \multirow{7}{*}{ GHQ 2: Social dysfunction } & 3) felt you couldn't overcome your difficulties? \\
\hline & 4) been feeling unhappy or depressed? \\
\hline & 5) been able to concentrate on whatever you're doing? \\
\hline & 6) felt that you were playing a useful part in things? \\
\hline & 7) felt capable of making decisions about things? \\
\hline & 8) been able to enjoy your normal day-to-day activities? \\
\hline & 9) been able to face up to problems? \\
\hline \multirow{3}{*}{ GHQ 3: Loss of confidence } & 10) been feeling reasonably happy, all things considered? \\
\hline & 11) been losing confidence in yourself? \\
\hline & 12) been thinking of yourself as a worthless person? \\
\hline
\end{tabular}

Answer:

not at all; no more than usual; rather more than usual; much more so than usual 